\author{
Petar B. Grujičic**
}

Fakultet savremenih umetnosti, Beograd

\title{
PROBLEMI SCENSKE AKTUELIZACIJE U KOMEDIJAMA VACLAVA HAVELA
}

Tekst razmatra Havelove drame kao istaknute izdanke takozvane disidentske dramaturgije, imajući u vidu tradicijski, žanrovski i performativni kontekst ove tematske oblasti. Sve do devedesetih godina dvadesetog veka, Havelovi komadi, iako zabranjeni u Čehoslovačkoj, često su izvođeni u inostranstvu, posebno u SFRJ, da bi potom za njih opalo interesovanje. Koji su razlozi te promene? Tekst navodi neke od njih: protivurečne žanrovske osobenosti, istorijsku uslovljenost teme, idealizovane aspekte biografije pisca u recepciji publike i dr. Dat je poseban osvrt na uticaj Havela na srpski teatar kao primer razgradnje disidentske dramaturgije u novom društvenom i teatarskom kontekstu. Ujedno, Havelove drame se razmatraju i u svetlu modernih tendencija da se politički teatar, i ne samo on, izmesti van kategorija klasičnog verbalnog, pa čak i dramskog teatra.

Ključne reči: disidentska drama, komedija, politički teatar, distopijska drama, istorija drame i pozorišta.

U pogovoru za svoje prevode drama Vaclava Havela, Aleksandar Ilić navodi bogatu hronologiju njihovih izvođenja na beogradskim scenama u razdoblju od preko dve decenije, počev od sredine šezdesetih godina prošlog veka. Njih režiraju naši najistaknutiji reditelji, a Havelove jednočinke i komad Largo desolato čak imaju ponovljene inscenacije. ${ }^{1}$ Godina 1989 , međutim, veliki je preokret ne samo za Havela koji, pravo iz disidentske ilegale postaje predsednik Čehoslovačke, već i za njegove drame. One tada napokon dobijaju mogućnost da budu objavljene i izvedene u domovini, ali iza toga njihov život počinje postepeno, a onda sasvim da zamire na ovdašnjim scenama. Tako već 1991. godine u jednoj od svojih pozorišnih kritika Jovan Hristić zlurado konstatuje kako je disidentska dramaturgija, misleći pritom na Havela i njegovu generaciju pisaca drama o istočnoevropskim disidentima, posle pada gvozdene zavese „iskopnela brže od lanjskog snega“" (Hristić 1996: 244).

Istorijska uslovljenost disidentske dramaturgije, tj. da više nema ni Hladnog rata ni njegovih disidenata, već sama po sebi sluti odgovore na pitanja o dometima njihove tematske aktuelizacije na pozorišnim

petar.grujicic@fsu.edu.rs

1 Srpske i jugoslovenske praizvedbe Havelovih komada režiraju Ljubomir Draškić, kao i Želimir Orešković i Dejan Mijač u Narodnom pozorištu i Ateljeu 212. Poslednju beogradsku postavku Havela na redovnom repertoaru, Largo desolato pod promenjenim naslovom Nepodnošljivo lako, režirao je Egon Savin 1989. godine. 
scenama. Ali kao što ćemo videti, današnje čitanje Havelovih drama i već poluvekovna distanca od njihovog nastanka otkrivaju nam pojedine osobenosti koje još više ograničavaju njihov, i ne samo njihov scenski život u savremenom pozorišnom kontekstu.

Ko god je krajem osamdesetih godina imao prilike da pohađa predavanja Aleksandra Ilića na beogradskom Filološkom fakultetu, mogao je da se uveri u osobit akademski diskurs koji je čak i antičku dramu, kao i čitave oblasti iz istorije književnosti bio sklon da tumači kroz prizmu antitotalitarnih i antistaljinističkih kritika, inspirisanih izneverenom utopijom, koja je - i za Ilića, i za Havela - bila neposredno životno iskustvo i jedna vrsta generacijske frustracije. Na tragu sličnih akademskih afiniteta, odsudne 1989. objavljen je i Zaplet budućnosti Dragana Klaića, monografija o distopiji u modernoj drami, gde, između ostalog, nailazimo i na prikaz Havelovog Memoranduma kao lingvističke distopije. U ovoj, jednoj od prvih Havelovih drama (1965), Klaić razmatra birokratsku kampanju nasilnog uvođenja izmišljenog govora koji, umesto da komunikaciju učini optimalno racionalnom u državnom birou gde se komad odigrava - dovodi do nesporazuma koje okončava tek pojava nove, jednako iracionalne reforme „novogovora“ čiji je isključivi smisao opstanak totalitarne birokratije, čak nezavisno od anonimnih autoriteta koji je inspirišu (Klaić 1989: 213-217).

Inače, koren distopijske moderne drame Klaić u Zapletu budućnosti otkriva u jednom kuriozitetnom romantičarskom remek-delu Imrea Madača, Čovekovoj tragediji (1861) (isto: 9-10). Imajući u vidu sklonost današnjih repertoara da totalitarne mehanizme istražuju upravo u tragedijama romantizma, za osvrt na Madačevo delo osećamo potrebu i zbog onih njegovih osobenosti koje iz današnje perspektive prepoznajemo kao (već tada) naznake procesa jedne dubinske dekonstrukcije u trajanju od skoro poslednja dva veka, a Peter Sondi ih u svojoj znamenitoj Teoriji moderne drame iz 1956. godine, na primerima više dramskih autora i novih dramaturških postupaka, naziva krizom i „pokušajima spasavanja drame“. Radnja Madačeve romantičarske misterije prikazuje Lucifera koji Adama, prvog i poslednjeg čoveka na zemlji, vodi na imaginarno putovanje kroz istoriju u kojoj mu dodeljuje uloge raznih istorijskih ličnosti (Miltijada, Tankreda, Dantona, Keplera i drugih), ali gde je zbog pluraliteta svojih identiteta, Adam takođe u dramskoj funkciji Jedermana, običnog pojedinca koji pod maskama slavnih protagonista iz scene u scenu traži pogrešne oslonce $u$ jednom već zadatom katastrofičnom scenariju. Kuriozitet Čovekove tragedije je do sada najviše dovođen u vezu sa njenim poslednjim scenama koje se odigravaju u dalekoj, visoko tehnologizovanoj budućnosti, čak van Zemlje - kao predikcija tragičnih 
posledica čovekove nemogućnosti da ovlada destruktivnim silama istorijskog procesa. Zanimljivo je da primetimo i to da, za razliku od romantičarskih drama koje u istočnoj i srednjoj Evropi u devetnaestom veku mahom nastaju na talasu nacionalnih pokreta - ovaj komad sa mađarskom istorijom vezuje samo pominjanje Sibinjanina Janka u svega jednoj prilici (Madač 2009: 149), dok se istorijski događaji u srednjoj Evropi vezuju isključivo za Prag, i to u čak dve, u osmoj i desetoj od ukupno petnaest scena. ${ }^{2}$

Osim te središnje teme o uzaludnosti svih društvenih projekata, disidentskoj dramaturgiji u romantizmu nalazimo preteču i u kultu individualizma, spremnosti pojedinca-izopštenika da se usprotivi društvu i da za to podnese posledice. Uprkos vremenskom razmaku od preko jednog veka, pažnju jednako privlači i donekle slična pozicija u distanciranju od pozorišne scene: dok romantizam odbija sva klasicistička, pa čak i melodramska načela, i stvara drame kao literaturu za čitanje, a ne za inscenaciju - disidentska dramaturgija je u zemljama svog porekla jednostavno zabranjena i za izvođenje i za publikovanje. Ali dok je u prvom slučaju odvojenost teksta i scene radikalna i organska, unapred prihvaćena od strane dramskog pesnika, u drugom je slučaju nasilna, frustrirajuća i, u suštini, privremena, sa određenim teatarskim, pa čak i teoretskim implikacijama koje ovo dramsko nasleđe, kao što ćemo videti, dovodi u središte savremenih rasprava o opstanku dramskog teatra.

Havelove drame u prevodu Aleksandra Ilića otkrivaju lako uočljivu podelu na dve grupe koje se razlikuju po obimu, tj. scenskom trajanju, ali i po strukturi: u prvoj grupi su velike, celovečernje alegorije o apsurdu totalitarnih diskursa unutar „velikog mehanizma“ istorije - da se poslužimo proslavljenom metaforom Havelovog srednjoevropskog teatarskog savremenika Jana Kota, prvi put predstavljenu 1965. godine u predgovoru Šekspira našeg savremenika (Kot 1990: 12) - dok su u drugoj grupi jednočinke, humorni dramoleti iz života disidenatapisaca. U obe grupe, naročito u celovečernjim dramama, primećujemo šturo dokumentovanje miljea, pa zato o realijama života iza Gvozdene zavese danas iz njih saznajemo začuđujuće malo toga. Radnja-alegorija mahom je smeštena u središte bezličnih birokratija čiji su reformatorski projekti preambiciozni i apsurdni, dok je realizam prisutan samo na planu dijaloga. Osim pomenutog Memoranduma, u Iskušenju (1985) posmatramo rad instituta koji na dosta neodređen način promoviše naučni, materijalistički pogled na svet, a u Asanaciji (1987)

2 Iako retko igrana u srpskim pozorištima, Čovekova komedija je više puta prevođena na srpski jezik, u prevodima Jovana Jovanovića Zmaja (1890), Todora Manojlovića (1939) i Stefana Stefanovića (1940). Ovom prilikom koristimo prevod Save Babića (2009), u izdanju književnog društva „Madač“ iz Budimpešte. 
- arhitektonski atelje koji u ime unapređenja standarda modernog stanovanja ulazi u glomazne građevinske poduhvate, koji unesrećuju i život stanara, i život arhitekata. Izuzetak je realistička komedija Largo desolato (iz „orvelovske“ 1984. godine). Za razliku od ostalih Havelovih drama, koje prikazuju grupu likova unutar birokratske hijerarhije koja ih skoro potpuno definiše, filozof Leopold Koprživa je u ovoj komediji izraziti protagonista koji se svojim usamljenim činom, ma koliko da je ovaj bojažljiv i dvosmislen (objavljivanje kritičkog eseja pod benignim naslovom Ontologija ljudskog ja) - suočava sa neizbežnim, ali i dalje samo (ne)slućenim posledicama. On je pod pritiskom anonimnih službenika koji ga ohrabruju da ne popusti u svom principijelnom stavu, ali i anonimnih doušnika koji od njega zahtevaju demanti da je on autor pomenutog eseja. Ono što Leopolda, međutim, najviše ugrožava nije toliko opasnost od statusnih ili fizičkih represalija, već odsustvo samopouzdanja, kao i tragikomična nemoć da se rasplete iz svojih zamršenih bračnih i ljubavnih odnosa. U duhu komedije, završetak donosi paradoksalan rasplet: Leopold odlučuje da principijelno ne popusti pretnjama, ali njegovi opskurni ucenjivači ga u poslednji čas obaveštavaju da im njegova saradnja nije ni potrebna, jer inkriminisani esej nije potpisan njegovim imenom, već pseudonimom.

U ostalim Havelovim celovečernjim dramama kompleksnost likova je još više pod senkom nevidljivog represivnog mehanizma, ali i raznih „komičnih šablona“, kako ih naziva Hristić, stereotipa, koje je naš značajni kritičar video kao veliku pretnju za čitav žanr koji naziva disidentskim komedijama (Hristić 1992: 277). Ovih šablona je i Havel ponekad svestan, kada na njih reaguju i likovi drame, poput mladog arhitekte Alberta iz Asanacije:

ALBERT: Znate, meni sve to izgleda malo nestvarno - ovaj zamak - ta asanacija - ti ljudi - kao da i nisu živi - više mi liče na likove iz neke šablonske pozorišne igre - čovek unapred zna šta ce reći i šta uraditi (Havel 1990: 135).

Žanrovsku prirodu ove predvidljivosti bismo najpribližnije mogli da nazovemo vodviljskom: odnosi likova su obično izukrštani ljubavni trouglovi, dok je svaki društveni konflikt prikrivena ljubavna kalkulacija u kojoj je teško razlučiti uzrok od posledice. Kao i u vodviljima, fizičko zadovoljstvo i materijalna dobit su manje-više neprikriveni cilj svih aktera, čak i onih sa intelektualnom reputacijom. Koliko je ovaj žanrovski aspekt primaran najbolje ilustruje Havelova prerada Opere za tri groša (1972), koja u poređenju sa prethodnim varijantama poznate dramske priče izgleda kao trijumf cinizma: u sukobu lopovskih klanova Makhita i Pičema, sa njihovim paralelnim ljubavnim aferama i obrtima, neprestano se menjaju uloge i savezništva, a da, zapravo, 
niko od njih ne zna čijem se autoritetu ili konačnom planu potčinjava. Suvereni mehanizmi totalitarne represije kod Havela, dakle, nemaju alternativu čak ni u svetu kriminala, a još manje u onom herojskom stavu koji je razbojničkom odmetništvu pridavao romantizam kao prethodnica disidentske dramaturgije.

Havelova potraga za adekvatnom alegorijskom formom često se oslanja i na parodiju. Osim u Operi za tri groša, parodični elementi su prisutni i u Iskušenju, komediji faustovske teme o doktoru Foustki, koji se, umesto da propagira naučni materijalizam - postepeno gubi u lavirintu svojih intelektualnih interesovanja vezanih za misticizam, pa čak i satanizam. Alegorijske strukture Havel kreira na različitim nivoima, kao u Asanaciji, na primer, u prepoznatljivom kafkijanskom ambijentu u podnožju srednjovekovnog zamka, gde je tematska inspiracija arhitektura, ili kako to otvoreno opisuje lik parodičnog imena Plehanov - „arhitektura kao samo ogledalo društva“ (Havel 1990: 179). Apsurd društvenog progresa u komadu razotkriva sopstveno naličje kao „sveopštu razmenu nesreće“, pri čemu sreća jednih zavisi od nesreće drugih: asanacija zamka će radi budućeg životnog standarda unesrećiti postojeće stanare i građane u sadašnjosti, a realizacija ljubavne veze arhitekte Lujze sa mladim Albertom uzrokovaće patnju i najposle samoubistvo Plehanova.

Tako pokušaji izlaska iz začaranog kruga apsurdne represije pretvaraju Havelove likove u jeretike čije unutrašnje iskustvo postaje glavna teškoća u scenskom prikazivanju. Usklađivanje intelektualne, introspektivne prirode protagonista sa komediografskim šablonima ne prolazi uvek glatko, naročito u korišćenju scenskog govora. Largo desolato je ovde ponovo najuspeliji primer, pa tako u raspravi sa prijateljicom Lusi, koja hoće da od njega izmami ljubavnu izjavu, Leopold priznaje:

Fenomenologija me je naučila da se trajno trudim da svojim tvrđenjima ne prekoračujem okvire izrecivog iskustva. Više volim da izrazim manje od onog što osećam, nego da rizikujem manifestaciju nečega što ne osećam (Havel 1991: 289).

Ali šta lik zapravo oseća? To je zagonetka pre svega za samoga protagonistu, pa se čitav komad može shvatiti i kao njegovo dovijanje da to otkrije. U pojedinim scenama, u neuspehu da sebi odgovori na to pitanje, protagonista čak falsifikuje originalne načine na koji ga drugi vide: suočen sa sopstvenom prazninom, ali i sa intelektualnom navikom da sve definiše, on stanje svoje unutrašnje krize ispoveda supruzi i ljubavnici istovetnim rečima, pri čemu mu se ova druga divi na „prekrasnom izražavanju“, dok se, u stvari, radi o ponovljenoj tuđoj konstataciji-dijagnozi koju mu na početku komada iznosi prijatelj Obrlam. 
Pasivnost glavnog protagoniste je, međutim, izazov pre svega za Havela, koji se u spisateljskim rešenjima oslanja uglavnom na mehanizme komedije. Ti mehanizmi ocrtavaju protagonistu u ogledalu okoline, kroz govor drugih likova kao u Largu desolatu, ili kao u Asanaciji gde je lik protagoniste zapravo generacijski multiplikovan kroz različite uzraste unutar iste profesionalne hijerarhije (stariji arhitekta Plehanov posmatra Alberta kao mlađu varijantu samoga sebe, i u profesionalnom, i u privatnom smislu, kada se ovaj upusti u aferu sa Lujzom). Ali komediografski mehanizmi su ujedno i šabloni koji predvidivo ponašanje likova otkrivaju kao (bez)moralne paradokse, a ne kao psihološku ili misaonu složenost na koju njihova intelektualna priroda pretenduje. Jedan od tih šablona je vodviljski promiskuitet unutar bračnih ili ljubavnih trouglova, što likovima već unapred oduzima unutrašnju težinu i autentičnost njihovog ispoljavanja. Tako u Iskušenju naučnik Foustka pristaje na nagovor mistika Fistule da mu, uz pomoć magičnih moći, na predstojećoj zabavi njihovog instituta omogući ljubavnu vezu sa mlađom koleginicom, a kada se to zatim i dogodi, Foustka tvrdi da se devojka u njega zaljubila slučajno, što Fistula odmah prevodi na jezik ezoteričnih doktrina koje takvu mogućnost negiraju. Iako sa suprotnih filozofskih polazišta, dakle, obojica koriste istovetan jezik jalovog, knjiškog filozofiranja koji je čest u Havelovim dramama, ali današnji gledalac nije dovoljno siguran da li je taj jezik komički govor ili možda samo (ne)preživeli oblik nescenične raspričanosti koja je plaćala danak intelektualnim afinitetima svog doba.

Tako na mnogim mestima vidimo kako se elementi diskusione drame i alegorije kod Havela ukrštaju sa svetom komedije na protivurečne načine, uzajamno se potirući. Komediografski šabloni posredno otkrivaju ono što likove Havelovih disidenata najviše kompromituje, mnogo više od njihove potencijalne (ne)spremnosti za društvenu diverziju, a to je odsustvo unutrašnjeg života, njihovog unutrašnjeg sadržaja. Otuda potiču i dva najčešća oblika njihovog govornog ispoljavanja: kroz glomaznu raspričanost i jalovo filozofiranje, ili kroz ćutanje i kratke, neodređene ili dvosmislene replike sa registrom različitih stanja zbunjenosti, nemoći ili čak straha da se održi banalna konverzacija. Zajedničko za obe vrste je da nemaju podtekst - u prvom slučaju intelektualna priroda likova nastoji da potpuno racionalizuje i definiše situacije, dok se u drugom slučaju lik zaustavlja pred nemogućnošću bilo kakve intersubjektivne razmene, pa više ne poseduje nikakav suvisli vokabular da opiše stanje unutrašnje praznine $u$ prepuštenosti samome sebi.

Dok su dramske pauze i ćutanja u modernoj dramaturgiji značenjske praznine koje naseljava podtekst, kod Havela, dakle, pronalazimo 
nešto sasvim suprotno - mrtve tačke, zid pred kojim se scenski odnosi zaustavljaju, petrifikuju. Sve nas to dovodi do još jedne iznenađujuće pojave u Havelovim komedijama, a to je da u njihovom personalu nema ketmana - intelektualca-glumca, društvenog kameleona ili autoriteta-Tartifa, kao jedne od središnjih kategorija u intelektualnom životu iza gvozdene zavese o kojima je svojevremeno pisao Česlav Miloš, a čija dvostruka suština kao da je i više i lakše prizivala teatarsko uprizorenje od prototipova Havelovih disidenata i njihovih antagonista, konformista-birokrata.

No uprkos pomenutim ograničenjima, dramski kapaciteti Havelovih jednočinki se utoliko više otkrivaju kao iznenađujući iskorak ka njihovom prevazilaženju. ${ }^{3}$ Sve one zapravo prikazuju jedan lik, disidenta u različitim životnim situacijama kao fragmente, isečke stanične dramaturgije koju su repertoarske postavke odmah prepoznale kao zgodnu mogućnost za „scene u nastavcima“, tj. za spajanje u celovečernje celine, a da se jedinstvo lika ne naruši. ${ }^{4}$ Katastrofa je u njima najčešće tačka neizgladivog sukoba disidenta sa antagonistom-konformistom, raspad njihovog odnosa koji podizanje zavese zatiče kao prisnost. Tako se u Vernisažu (1975) ili Protestu (1978) radi o likovima iz istog miljea, čak istomišljenicima, gde se protagonista i antagonisti mogu opisati kao životne faze „posle“ $\mathrm{i}$ „pre“ jedne iste personalnosti (otud sličnost njihovih imena Sladek-Vanjek, Stanjek-Vanjek), rascepljene iskustvom disidentske izopštenosti. Ta se iskustva, primećujemo, navode prilično šturo, kao boravci u istražnom zatvoru ili karijerna degradacija, poput rada u pivari koja kod Havela postaje svojevrsni disidentski toponim, ali sve to bez ikakvih konotacija torture, nasilja ili represije. Zato se lik Havelovog disidenta u očima gledalaca ne otkriva toliko kao gubitnik zbog svoje traume iz skorašnje prošlosti, koliko zbog traume koju upravo preživljava na sceni, a koju radnja jednočinke fokusira kao nemogućnost povratka u zonu svakodnevnog komfora koju oličava antagonista.

Najbolji primer toga nalazimo u Vernisažu, gde bračni par pokušava da svog traumatizovanog prijatelja-disidenta oraspoloži navođenjem

3 Peter Sondi je formu jednočinke shvatao kao pokušaj „spasavanja drame“, što se u Havelovom slučaju potvrdilo kao mogućnost. Govoreći o katastrofi kao futurističkoj datosti dramske radnje, Sondi primećuje da jednočinke prikazuju granične događaje koji govore „o situaciji pre katastrofe koja zapravo predstoji već sa podizanjem zavese i tokom narednog zbivanja više ne može da bude izbegnuta", pa se tako ,jednočinka u toj formalnoj tački potvrđuje kao drama čoveka koji nije slobodan" (Sondi 2008: 110). I zaista, kontekste te neslobode nam jednočinke znatno uspešnije otkrivaju nego Havelove alegorije.

4 Repertoarske postavke ne spajaju samo Havelove jednočinke u celovečernje predstave, već ih kombinuju i sa disidentskim komedijama drugih autora, poput Pavela Kohouta, pa se tako u jednom beogradskom izvođenju Kohoutov Arest izvodio uz Havelov Protest (Narodno pozorište, 1984. godine). 
brojnih detalja u preuređenom enterijeru njihovog stana, uz sijaset banalnih recepata za uspešan bračni i seksualni život iz domena popularne psihologije. Čak i u Audijenciji (1975), koja se odigrava u neuglednoj kancelariji, tu zonu komfora komično prezentuje antagonista Sladek, direktor pivare, svojom opsesijom o poznanstvu sa poznatom glumicom koju će da mu omogući protagonista Vanjek. Na sličan način, radnja u Protestu se odigrava u raskošnom, negovanom kućnom vrtu, a peticija oko čijeg potpisivanja izbija sukob između nekadašnjih prijatelja tiče se kantautora, člana estradnog imaginarijuma koji nevidljivo amortizuje i prepokriva totalitarnu suštinu društvenog konteksta. Likovi antagonista, razume se, ostaju slepi za tu realnost koju protagonisti ne znaju da iskažu, što je osnov komičnih nesporazuma čiji obrazac Hristić u jednoj od svojih kritika opisuje ovako:

Na sve te priče i bezbrojna, uglavnom glupa i uvredljivo radoznala pitanja, Vanek odgovara kratkim i uzdržanim rečenicama između kojih se prostiru ogromne pustoši ćutanja. A kako bi drukčije i mogao čovek koji se odjednom našao izgnan u jedan drugi svet, čiji je život sada postao toliko drukčiji od života ljudi sa kojima se sreće? (Hristić 1982: 308)

Taj drugačiji život Havelovog disidenta ponovo priziva poređenja sa već pomenutom tradicijom moraliteta o Jedermanu kao protagonisti koji, suočen sa spoznajom smrti, nailazi samo na lažne prijatelje i oslonce. Tako na završetku Vernisaža, u rečima kojima se bračni par oprašta od lika Vanjeka, naziremo čitav jedan katalog personifikovanih lažnih vrednosti, nalik dramatis personae iz Jedermana, likovima koji glavnog protagonistu izneveravaju pred transcendentnom spoznajom van svakodnevnog opažanja, spoznajom smrti:

MIHAL: Hteli smo da ti pružimo malo porodične topline koja ti kod tvoje kuće nedostaje. - VERA: Da te usmerimo na druge misli - MIHAL: Da te za trenutak izvučemo iz tog marazma u kojem živiš VERA: Da te malo postavimo na noge - MIHAL: Pomenemo ti razne ideje kako da se ispetljaš iz te svoje situacije - VERA: Da ti pokažemo šta je sreća - MIHAL: Ljubav - VERA: Porodična harmonija - MIHAL: Život koji ima smisao - VERA: Znaš da ti želimo najbolje - MIHAL: Da te volimo - VERA: Da si naš najbolji prijatelj - MIHAL: Pa ne možeš valjda da budeš toliko nezahvalan! (Havel 1991: 239)

Poređenje smatramo umesnim i zato što se u moralitetima kao i u ostalim vrstama poučnih scenskih dela koja se nadovezuju na ovu tradiciju do današnjeg doba - fokus dramske radnje - uvek upadljivije za gledaoca nego za čitaoca - sa protagoniste premešta na antagonistu. Za razliku od pasivnog protagoniste, antagonista je i kod Havela scenski aktivan u svojim ispoljavanjima, sa primetno većim 
ludičkim potencijalom, i mada u dramskoj postavci sve vreme ostaje u funkciji antagoniste, on uvek pokazuje specifične tendencije za osamostaljenjem koje najposle dovode $u$ pitanje i poziciju antagoniste, čineći je ambivalentnom ili čak lažnom. U tom smislu, Havelove jednočinke kao vrsta stanične dramaturgije dozvoljavaju piscu i određene samorefleksije, poput one u Protestu kada Stanjek kaže Vanjeku da je sa suprugom već pročitao njegovu jednočinku koju naziva „ono iz pivare“, da bi zatim uputio dvosmislen kompliment: „To je zaista briljantno delce! Samo mi kraj izgleda malo nejasan, čini mi se da to teži jednoznačnoj poenti - pa bar vi to umete!“ (Havel 1991: 235)

Stanjek, jasno je, očekuje „jednoznačnu poentu“ kao satiričnu poruku, ali koju ni Vanjek ni čitava Havelova dramaturgija ne nude, uprkos utisku da teže ka tome. Očekivanje ostaje iznevereno, jer kod Havela, ispostavlja se, nije ni moguć klasični sukob, agon između ravnopravnih scenskih sučeljenosti. Ono što protagonistu čini istinski neslobodnim i drži ga u začaranom krugu dramske pasivnosti nisu toliko sile spoljašnje, društvene represije, već indirektna posledica delovanja tih sila: uvid u nedostatak dosledne, celovite individualne psihologije, ispunjene samo protivurečnim, mahom infantilnim željama i zaokupljenostima, ali čija se na izgled mala snaga na kraju pokazuje kao trijumfalna i zaprepašćujuća.

Otuda postaju jasniji i razlozi zašto su Havelove drame danas redak gost na repertoarima. Čak i kada bismo pronašli adekvatne tematske aktuelizacije kao „prevode“ njihovog društvenog sadržaja (na primer: kada bismo motive kao što su objavljivanje kritičkog članka ili potpisivanje peticije preveli kao subverzivne aktivnosti na elektronskim društvenim mrežama, ili profesionalnu degradaciju Havelovih disidenata kao tavorenje nekog od nezaposlenih doktora nauka na biroima rada i sl.), nedostatak ,jednoznačne poente“, te fatamorgane svakog političkog teatra, Havelovu dramaturgiju stavlja van domašaja bilo kakve konkretne politizacije. Dodatna poteškoća se krije i u tome što je disidentska dramaturgija verovatno poslednja evropska pozorišna tradicija koja je svoju reputaciju zasnivala na idealizovanim aspektima biografije njenih pisaca. Dignitet protagoniste-disidenta u očima gledališta, njegova kakva-takva nadmoć i oreol herojstva na sceni su počivali takođe i na autoritetu autora, na autentičnosti njegove životne traume koju je gledalište manje ili više uzimalo u obzir i pre odlaska u pozorište, iako dramska kriza kod Havela, kao što smo se uverili - i to na nemalo iznenađenje današnje publike - zapravo i nije prikazana kao principijelno društveno delanje, već kao nemogućnost povratka u svakodnevnu zonu komfora.

Šta, dakle, preostaje u recepciji ovih drama kada se one, pre ili kasnije, oslobode biografije pisca kao svoje parateatarske datosti? 
Koliko su one u stanju da funkcionišu bez te pupčane vrpce koja ih najvidljivije veže za njihov istorijski kontekst?

Odgovor na ovo možda najteže pitanje povodom disidentske dramaturgije može da ponudi i razmatranje o uticaju koji je Havel imao na srpski teatar. Retko se koji inostrani pisac mogao pohvaliti tolikim uticajem na ovdašnji pozorišni život, zbog čega Ilić u više navrata ističe da je Havel, u godinama kada su njegovi komadi bili zabranjivani u Čehoslovačkoj, „kod nas našao drugu domovinu“ (Ilić 1991: 346). Pogodnost je između ostalog bila i u tome što je naš posleratni teatar već imao jednog „Havela pre Havela“, Velimira Lukića i opus njegovih satiričnih alegorija, tragikomičnih farsi čija se radnja odigrava u kraljevstvima iz udaljene, nedefinisane prošlosti, o totalitarnim društvima u čijem središtu su i likovi intelektualaca, potencijalnih ili stvarnih buntovnika-disidenata (Afera nedužne Anabele, Dugi život kralja Osvalda). Ali dok je Lukić alegoriju koristio kao „ezopovski“ jezik, zaobilazni način da se na sceni iznese kritika čije bi otvoreno iznošenje provociralo cenzuru, Havel je, naročito u svojim poslednjim komadima, mogućnosti alegorije ispitivao bez te pretpostavljene scenske recepcije, naprosto znajući da je zabranjen pisac. To prinudno apstiniranje od scene je, kao što smo videli, Havelove drame okrenulo ranijim tradicijama, ali i tendencijama neliterarnog pozorišta za koja smo danas u iskušenju da ih nazovemo postdramskim, imajući pre svega u vidu široku, skoro neograničenu kumulativnost tog pojma u današnjoj teatrologiji. Tu pre svega mislimo na upotrebu muzike, čime se ovde nećemo baviti, potom na ludičke aspekte komedije, kao i na upotrebu kafkijanske alegorije čije potencijale dramski teatar tek tih decenija počinje da ispituje, a za koju Havel, „čovek kafkijanske sudbine“ - kako ga naziva Ilić (Ilić 1991: 348) - pokazuje izrazitu intimnu naklonost.

Neposredan uticaj Havela na srpsku dramu je, međutim, ostao najvidljiviji u delu Dušana Kovačevića, središnje figure naše posleratne drame, za koga je krajem osamdesetih Havel veliki pozorišni i intelektualni uzor. Kao rezultat tih neskrivenih simpatija nastaje Profesionalac (1990), komedija o policajcu koji posećuje pisca koga je godinama uhodio, da bi se sa njim napokon upoznao i od njega se pred smrt oprostio. U komediji lako prepoznajemo obrazac Havelovih jednočinki o disidentu i oportunisti, ali i načine uz pomoć kojih Kovačević nadograđuje taj odnos. Kovačevićev Teja Kraj više nije Havelov Jederman, već plastično prikazana ličnost sa javnom i privatnom biografijom, i to upravo zahvaljujući antagonisti Luki Labanu, svojevrsnom kolekcionaru njegovih privatnih i javnih uspomena čije nizanje tvori liniju dramske naracije. Tako Kovačević u Profesionalcu vrši svojevrsni eksperiment u monološkoj formi (u komadu su čak i 
didaskalije pisane u prvom licu jednine, kao ispovesti), gde su protagonista i antagonista zapravo polovine jedne iste personalnosti, koje se na humoran, emocionalno dirljiv način međusobno prožimaju. Kod Kovačevića čak izostaje i katastrofa na kraju, pa jednočinka okončava u pomirljivom tonu, a fokus radnje se samosvesno usmerava na antagonistu koji je i kod Havela često bio u stanju (ali bez namere pisca, verovatno čak uprkos njoj) da glavnom liku „ukrade šou" pred gledalištem. 5

Zato, u kontekstu poređenja, Kovačevićevu komediju možemo razumeti i kao radikalan odgovor, dovođenje do krajnjih konsekvenci jedne potrage za identitetom kao osnovne težnje Havelovih likova-disidenata. Koliko je, međutim, tačka ukrštanja Havela i Kovačevića u Profesionalcu bila prelomna pre svega za Kovačevića, govori i to da posle Profesionalca njegova komediografija poprima dominantnu monološku, hermetičnu, u nekim aspektima čak autističnu formu koja više nije bila u stanju da obnovi svoje impozantne početke ${ }^{6}$, dok istovremeno Havelova pozorišna zvezda počinje sve više da gasne, pa tako njegova dela skoro da više ne privlače dotadašnju pažnju, naročito na srpskim scenama, gde pisac, zbog svojih predsedničkih istupanja tokom postjugoslovenskih ratova, postaje persona non grata.

U potonjem periodu, lik intelektualca-disidenta postaje sve ređi u delima srpske dramaturgije, da bi svoje opelo dočekao u jednom komadu internacionalne reputacije, u Supermarketu Biljane Srbljanović, iako se tih godina i sama autorka u delu inostrane javnosti percipirala kao disidentkinja. Supermarket praizvedbu doživljava na bečkoj Šaubine 2001. godine, a odmah potom se postavlja u Srbiji, a onda i širom inostranstva kao jedan od najizvođenijih komada čitave srpske dramaturgije. Radnja komada se odigrava deset godina posle pada Berlinskog zida, a glavni lik Leo Švarc još uvek parazitira na svojoj disidentskoj reputaciji kao direktor osnovne škole u nekoj zapadnoevropskoj državi, u koju je svojevremeno emigrirao. Spisateljica provocira idealizovan biografski aspekt disidentskog diskursa, pa tako Švarca prikazuje kao osobu erodiranog autoriteta, čija prošlost se ispostavlja kao lažna (čak je i svoje aforizme falsifikovao od Havela, uz nadu da mu ovaj neće tražiti obeštećenje za autorska prava). Jedino što je u Supermarketu podložno promeni, ulepšavanju i idealizaciji je

5 Zanimljivo je da su u Beogradu Havelove jednočinke bile praizvedene u režiji Ljubomira Draškića na sceni Ateljea 212, od strane istog reditelja i pozorišta koje je tih godina praizvodilo i Kovačevićeve komade. Takođe i Sladeka u tumačenju glumca Bate Stojkovića, iz postavke Protesta iz 1981. godine, možemo razumeti kao svojevrsnog preteču njegove deset godina kasnije proslavljene uloge Luke Labana iz Profesionalca.

6 O tome više u: Grujučić 2004: 71-76. 
Leova biografija, njegov disidentski curriculum vitae na osnovu sačuvanog policijskog dosijea, i to zahvaljujući narativnoj formi komada koji se odigrava kao ponavljanje jednog istog dana u njegovih sedam varijanti, tj. dana-činova. No baš tu, u posezanju za metateatralnom i metaleptičnom naracijom o „večitom ponavljanju“, opet srećemo formalne nesrazmere iz Havelovih alegorija, gde se satiričke strele zaogrću u preveliko ruho filozofskih ili ezoteričkih diskursa. To i u Supermarketu tvori česte žanrovske i narativne distorzije, pa poput Havela koji rabi šablone vodvilja u psihološkom svođenju likova nauštrb njihove uverljivosti, tako i Srbljanovićeva koristi šablone tv-sapunica, ali i stereotipe jedne još grublje, mizantropske tipologije koja već tada naseljava njen dramski opus (psihotična deca, impotentni ljubavnici, perverzni roditelji i dr.). Na planu kompromitacije disidentske dramaturgije, međutim, ovo se pokazalo kao prilično delotvorno, i to ne toliko zbog ocrnjene intime glavnog protagoniste, već zbog jednog neočekivanog otkrića: aktivne pozicije koju u strukturi komada zadobija na izgled običan curriculum vitae iz nekadašnjeg policijskog dosijea kao paradoksalni preokret u kojem tekst biografije, iako objekat manipulacije - na kraju zadobija autonomna, čak nadlična svojstva u poređenju sa fiksnom psihologijom likova, koja, međutim, potencijale njihove scenske aktuelizacije danas čini još užom nego kod Havela.

Sve ovo naša razmatranja seli na teren danas (još uvek) gorućih pitanja o opstanku dramskog teksta u savremenom teatarskom kontekstu, gde nasleđe disidentske dramaturgije možemo razumeti kao još jedan od pokušaja spasavanja drame u dvadesetom veku, ovoga puta zahvaljujući iskustvima autentične traume na razvalinama jedne izneverene političke utopije. Primećujemo, međutim, da su ovi komadi u dužem razdoblju skoro potpuno van rediteljskih i repertoarskih interesovanja. Osim istorijske uslovljenosti koja limitira aktuelizaciju teme, jedan od razloga je svakako i taj što Havelove drame, kao izraziti primeri dramskog teatra, naročito one najuspelije poput Larga desolata i jednočinki, skoro da ne zahtevaju bilo kakvu rediteljsku arbitražu. Toliko je u njima tekst, čak i kada je ispunjen pauzama i ćutanjima, lišen svih značenjskih praznina, potpuno spreman za inscenaciju, što poziciju rediteljskog čitanja, toliko (pre)naglašenu u savremenom teatru, skoro da potpuno obesmišljava.

Još veći problem je, međutim, u uočenoj monološkoj tendenciji u scenskim ispoljavanjima Havelovih protagonista usled sve jasnije spoznaje da se uzroci i preduslovi totalitarnih mehanizama ne nalaze toliko u društvenoj realnosti, dakle - van pojedinca, već unutar njegove slabe, pasivne ili nepostojeće individualne psihologije kao antropološke činjenice. U isti mah, danas smo svedoci paradoksa iz repertoar- 
ske prakse da su se upravo monološki narativi pokazali kao najviše rabljeni u praksi postdramskog teatra, naročito u oblicima političkih performansa, lišenih agona i sa porukama neposredno upućenim ka gledalištu, što je čitavu ovu oblast pomerilo više ka onim tradicijama koje su, poput romantizma, u prikazu totalitarnih diskursa gajile statičan, čak deklamatorski odnos prema tekstu. Upravo iz tih razloga Havelove komedije ne treba otpisati kao povod za buduce aktuelizacije: one su prve uočile da je zatvaranje lika u usamljeničke, monološke scenske okvire takođe i vid tabuiziranja čija je konačnica ukidanje same drame kao odnosa scenskih sučeljenosti, a čije utopijsko, beskonfliktno odsustvo je, zapravo, početak i kraj svake totalitarne (samo)hipnoze, i to ne u društvenoj stvarnosti, već u samom teatru.

\section{Literatura}

Grujičić, P. (2004). Fenomen demencije u komedijama Dušana Kovačevića. Beograd: Teatron, 126/127, 71-76.

Havel, V. (1990). Pazite! (drame: Iskušenje, Asanacija). Beograd: Dečje novine.

Havel, V. (1991). Šest drama. Beograd: Nolit.

Hristić, J. (1982). Pozorište, pozorište II. Beograd: Nolit.

Hristić, J. (1992). Pozorišni referati. Beograd: Nolit.

Hristić, J. (1996). Pozorišni referati II. Beograd: Nolit.

Ilić, A. (1991). Satirični Levijatan Vaclava Havela. Vaclav Havel, Šest drama. Beograd: Nolit. 345-352.

Klaić, D. (1989). Zaplet budućnosti. Zagreb: Cekade.

Kot, J: (1990). Šekspir naš savremenik. Sarajevo: Svetlost.

Miloš, Č. (1985). Zarobljeni um. Beograd: BIGZ.

Sarazak, Ž. P. (ur.) (2009). Leksikon moderne i savremene drame. Vršac: KOV.

Srbljanović, B. (2001). Supermarket. Beograd: Teatron, 116/117, 179-214.

Мадач, И. (2009). Човекова трагедија. Будимпешта: Књижевно друштво „Мадач“.

Ковачевић, Д. (1998). Одабране драме 2. Београд: Стубови културе.

Сонди, П. (2008). Студије о драми. Нови Сад: Орфеус. 
Petar B. Grujičić

Faculty of Contemporary Arts, Belgrade

\section{The Problems of Stage Actualisation in Vaclav Havel's Comedies}

\section{- Summary -}

The text analyses Havel's plays as the most prominent representatives of so-called dissident dramaturgy, considering its traditional, genre and performing context. Until the 1990s, these comedies, although forbidden in Czechoslovakia, were often performed abroad, especially in the SFRY, but afterwards they disappear from repertoires. What are the reasons for this change? The text lists some of them: contradictory genre peculiarities, historical conditionality of the topic, idealized aspects of the writer's biography, etc. Special attention will be given to Havel's influence on Serbian dramaturgy as an illustration of the decomposition of dissident dramaturgy in a new social and theatrical context. Also, Havel's plays are analysed on the basis of modern tendencies to shift political theatre, and not only it, beyond the categories of classical verbal and even drama theatre.

Keywords: dissident drama, comedy, political theatre, dystopian drama, history of drama and theatre. 